\title{
Sustainable Composites Based on Recycled High-density Polyethylene/mica
}

\author{
Priscila de Oliveira Almeida ${ }^{4}$, Camila Ferreira Gerardo ${ }^{4}$, Ariadne Gonçalves de Leão ${ }^{A, B}$, \\ Silvia Cristina Alves França ${ }^{C}$, Shirleny Fontes Santos ${ }^{A}$ and Daniele Cruz Bastos ${ }^{A *}$ (D) \\ ${ }^{a}$ Fundação Centro Universitário Estadual da Zona Oeste (UEZO), Avenida Manuel Caldeira de \\ Alvarenga, 23070-200, Campo Grande, Rio de Janeiro, RJ, Brasil \\ ${ }^{b}$ Universidade Federal do Rio de Janeiro, 21945-970, Rio de Janeiro, RJ, Brasil \\ ${ }^{c}$ Centro de Tecnologia Mineral (CETEM), 21941-908, Rio de Janeiro, RJ, Brasil
}

Received: September 15, 2020; Revised: December 28, 2020; Accepted: January 14, 2021

\begin{abstract}
Composites based on recycled high-density polyethylene (rHDPE) and muscovite mica, with different $\mathrm{rHDE} /$ mica ratios $(100 / 0,95 / 5,90 / 10,85 / 15$ and $80 / 20$, weight percentage) were prepared in an internal mixer with roller-type rotors at temperature of $170^{\circ} \mathrm{C}$ for 10 minutes. The materials obtained were characterized by tests of density, Shore hardness D and melt-flow index, along with infrared spectroscopy, thermogravimetry, differential scanning calorimetry and scanning electron microscopy. The hardness analysis confirmed the action of mica as a reinforcing load in the matrix, but this effect stabilized at around $15 \%$. The TG analysis showed that the $85 / 15$ composite presented slightly better performance than the $80 / 20$, indicating that mica, up to $15 \%$, caused disorganization of the polymer structure instead of reinforcing it. The DSC results revealed that the composites had slightly lower melting temperatures than the matrix. The FTIR spectrum indicated there was no chemical interaction between the rHDPE and mica.
\end{abstract}

Keywords: composites, plastic lumber, muscovite mica, recycled high-density polyethylene.

\section{Introduction}

Traditional plastics do not easily degrade in the environment. In particular, polymers require hundreds of years to degrade under normal environmental conditions. In addition, plastic wastes are harmful since their pigments contain many highly toxic trace elements ${ }^{1}$. However, post-consumer plastic waste can be used in many plastic lumber products, reducing the amount of material that must be discarded in landfills ${ }^{2,3}$.

Plastic lumber products are currently made predominantly with recycled polyolefin plastics (in particular high-density polyethylene), and are more or less non-homogenous in the cross-section. Currently, polyethylene ( $83 \%$ ), polypropylene (7\%) and polyvinyl chloride ( $9 \%$ ) are the main polymer matrices used in the manufacture of plastic lumber composites. These products have gained market share in various applications (decks, railings and automotive parts) due to their good mechanical properties, low costs and renewability ${ }^{3-5}$. However, because of their frequent use in the open air, these materials are subject to constant exposure to sunlight and inclement weather, thus causing a need for improvement in thermal and mechanical properties ${ }^{4}$.

A possible alternative is the reprocessing of plastic lumber with the incorporation of reinforcing fillers, that is, in the form of composites. Several types of materials have been studied for use as reinforcing fillers, such as glass and polymer fibers, calcium carbonate, plant fibers (sisal, coconut, jute, etc.), clay minerals (bentonite, montmorillonite, muscovite, etc.), and others ${ }^{3-8}$.

*e-mail: danielebastosuezo@gmail.com
The term mica is applied to a group of complex aluminosilicate minerals that have lamellar structure and different chemical compositions and physical properties ${ }^{7}$. In the group of micas, three subtypes are prominent - muscovite, phlogopite and biotite. In the northeastern region of Brazil, there are sizable reserves of muscovite, but the mining is mainly artisanal, which causes the mineral obtained to have low added value and generates environmental pollution. Muscovite, $\mathrm{KAl}_{2}\left[\mathrm{Si}_{3} \mathrm{AlO}_{10}\right]\left(\mathrm{OH}, \mathrm{F}_{2}\right)$ has many industrial applications, such as use in condensers, insulators, plastic fillers and pearlescent pigments ${ }^{9,10}$.

Martins et al. tested the use of an inorganic solid waste from the manufacture of fluidized-bed catalytic cracking catalysts as flame retardants in polymer-matrix composites of rHDPE. The results of the horizontal firing tests performed clearly showed that the incorporation of inorganic residue in the polymer material increased fire resistance ${ }^{3}$.

Lapčík et al. studied the effect of filler particle shape on the plastic-elastic mechanical behavior of virgin high-density polyethylene/mica and virgin high-density polyethylene/ wollastonite composites. They found that both fillers (mica and wollastonite) caused an increase in Young's modulus of elasticity with increasing filler concentration in a HDPEcomposite matrix ${ }^{7}$.

Turku et al. studied the influence of accelerated weathering, xenon arc light and freeze-thaw cycling on wood plastic composites (WPC) extruded from recycled plastic. The results showed that, in general, weathering had a stronger impact on samples made from plastic waste compared to a 
sample made from virgin material. Incorporation of carbon black reduced loss of properties during weathering, reduced the wettability of the sample, diminished the change of mechanical properties and improved color stability ${ }^{11}$.

Gerardo et al. studied the influence of mica (muscovite type) particle size (less than 45, 75, 100 and $125 \mu \mathrm{m}$ ) in a recycled high-density polyethylene (rHDPE) matrix on the wetting behavior and morphological, physical, and chemical properties. Thermal properties were not assessed. The results showed that properties of recycled HDPE were improved with mica addition. However, the variation of mica particle size studied did not significantly affect the properties of the rHDPE ${ }^{6}$.

The novelty of this work is to analyze the sustainable recycling of high-density polyethylene (rHDPE), in particular the improvement of its thermal and mechanical properties by adding mica (muscovite type), a mineral with low value, with fixed particle size (less than $100 \mu \mathrm{m}$ ), without use of a compatibilizing agent.

We decided not to use a compatibilizing agent because it would unduly increase the cost of the products made from the recycled materials, which would probably reduce interest in their use ${ }^{12}$.

The materials were processed in a Brabender internal mixer, and the rHDPE/mica composites were compounded in ratios of 100/0, 95/5, 90/10, 85/15 and 80/20 (weight percentage). The composite materials were characterized by scanning electron microscopy (SEM), thermogravimetry/ derivative thermogravimetry analysis (TG/DTG) and differential scanning calorimetry (DSC) as well as by determination of density, hardness and melt-flow index (MFI).

\section{Experimental Procedures}

\subsection{Materials}

The mica used in this work was collected in the region of Borborema-Seridó (straddling the states of Rio Grande do Norte and Paraíba) by staff members of the Mineral Technology Center (CETEM).

The mining of this mineral in the region studied is carried out without technical knowledge as a subsistence activity of people in the region, so the muscovite obtained has low value. This fact reinforces the sustainable character of this study, since the conduction of research into the uses of this mineral contributes to increase its value and reduce the environmental impact caused by its inadequate extraction.
The mica samples were treated according to the method developed at the CETEM ${ }^{9}$.

The mineral was milled with industrial knives until granulometry of less than $2 \mathrm{~mm}$. The resulting product was separated from impurities by table gravity concentration, where the impurities are removed by density difference while the material slides on a vibrating table. Then the purified product was ground in a laboratory knife mill and dry sieved to obtain material with granulometric classification less than $100 \mu \mathrm{m}^{9}$.

The plastic lumber waste (recycled high-density polyethylene, or r-HDPE) used in this work was provided by Companhia Municipal de Limpeza Urbana (Comlurb, the municipal sanitation agency in the city of Rio de Janeiro). The processing of the received material initially consisted of manual separation to eliminate coarse materials and sawdust residues. Thereafter, the material was manually cut into smaller sizes, to allow insertion into the feeder of the internal mixer. Finally, a magnet was introduced among the portions of cut material to remove small metal residues ${ }^{3}$.

\subsection{Composites preparation}

The composites were prepared in the following $\mathrm{rHDPE} / \mathrm{mica}$ ratios (weight percentage): 100/0, 95/5, 90/10, 85/15 and $80 / 20$, in a Brabender internal mixer with roller type rotors at a temperature of $170{ }^{\circ} \mathrm{C}$ for 10 minutes and rotor speed of $80 \mathrm{rpm}$. The torque and temperature values measured during the processing of all batches were monitored through a coupled computer. The coarse and deformed particles of each of the formulations produced in the internal mixer were then ground in a knife mill, generating smaller particles. Subsequently, the samples were pressed at $170^{\circ} \mathrm{C}$ in a Marconi MA 098/A hydraulic press to prepare the test specimens for the characterization tests. The Figure 1 shows a sketch of the experimental set-up for composite preparation.

\subsection{Characterization}

The mica crystal structure and morphology were previously investigated by Monsores et al. and the results revealed no changes in the crystal structure and maintenance of the lamellar structure ${ }^{13}$.

\subsubsection{Physical characterization}

The samples (r-HDPE, 95/5, 90/10, 85/15 and 80/20, percentage by weight) were characterized according to density (ASTM D792-08), hardness (ASTM D2240-05) and melt-flow index, MFI (ASTM D1238-10).

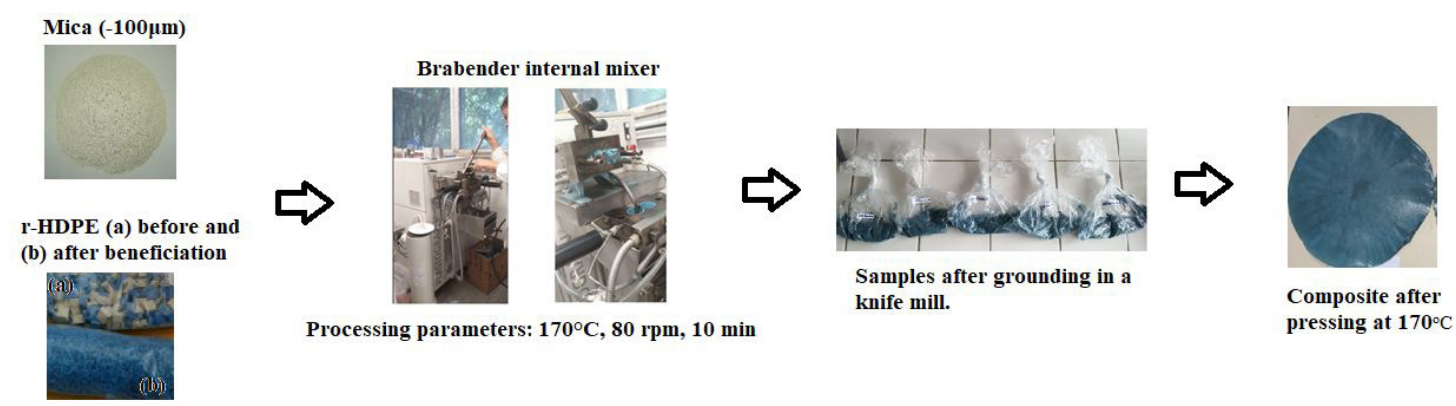

Figure 1. Sketch of the experimental set-up for composite preparation. 


\subsubsection{FTIR analysis}

Fourier-transform infrared spectra were acquired using a Nicolet 6700 FTIR spectrometer (Thermo Scientific). The samples were mounted on an attenuated total reflectance (ATR) accessory equipped with $\mathrm{ZnSe}$ crystal prior to scanning. The spectra were obtained with an accumulation of 120 scans and resolution of $4.182 \mathrm{~cm}^{-1}$.

\subsubsection{Thermogravimetry/derivative thermogravimetry (TG/DTG)}

The thermal stability of the samples was evaluated by thermogravimetry (TG/DTG) analysis, with a TA Instruments Q50 analyzer with platinum pan, using a temperature ramp from 30 to $700{ }^{\circ} \mathrm{C}$, heating rate of $10^{\circ} \mathrm{C} / \mathrm{min}$ and nitrogen atmosphere.

\subsubsection{Differential scanning calorimetry (DSC)}

The DSC analysis was performed using a TA Instruments Q100 instrument with platinum pan. The samples were analyzed under nitrogen atmosphere, with four cycles. In the first cycle, the sample was heated from 0 to $200^{\circ} \mathrm{C}$, at a heating rate of $10^{\circ} \mathrm{C} \mathrm{min}^{-1}$, keeping the material at $200{ }^{\circ} \mathrm{C}$ for $2 \mathrm{~min}$; in the second cycle, the sample was cooled at a rate of $10{ }^{\circ} \mathrm{C} \mathrm{min}-1$ until reaching $30^{\circ} \mathrm{C}$; in the third cycle, the same temperature range and heating rate of the first cycle were applied (except for the $2 \mathrm{~min}$ isothermal step); and in the fourth cycle, the same temperature range and cooling rate of the second cycle were applied. We considered the data of the second heating curves.

\subsubsection{Scanning electron microscopy (SEM)}

The SEM analysis was performed using a Tescan Vega 3 microscope to observe specimens coated with gold. Cryogenically fractured transversal sections of the samples were assessed, and the images were obtained at $1000 \mathrm{x}$ magnification.

\section{Results and Discussion}

Figure 2a-d shows the SEM results, indicating the random planar shape of mica filler particles. The matrix contained dispersed solid particles, explained by the fact of using recycled material that had been exposed to foreign materials
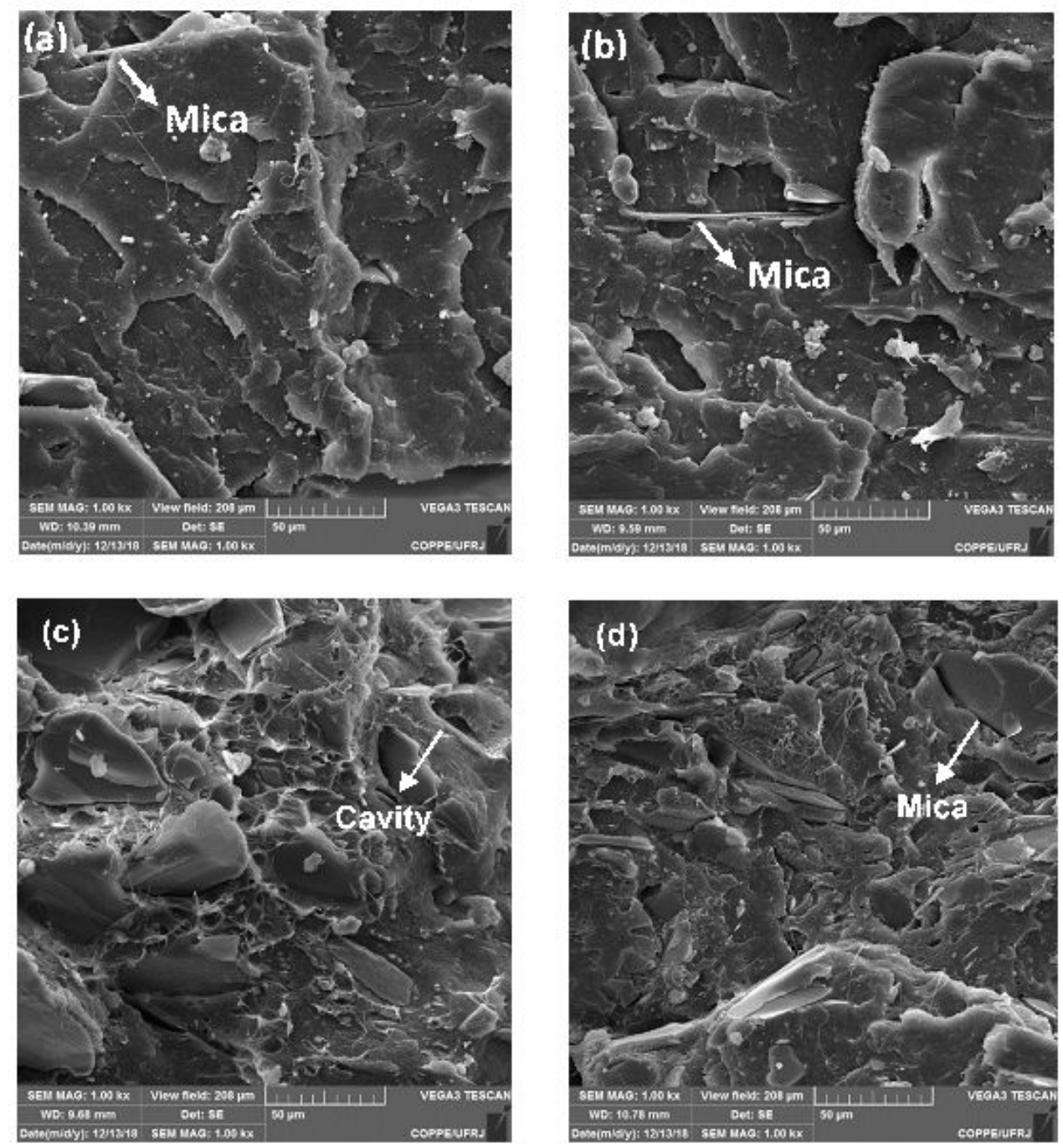

Figure 2. SEM micrographs of fractured surfaces of rHDPE/mica: (a) 95/5; (b) 90/10; (c) 85/15 and (d) 80/20 composite. 
and some additives, used to improve the reprocessing of the plastic lumber. There was relatively good adhesion between the filler and matrix, with few occurrences of small cavities around individual particles. This good adhesion of rHDP/ mica was not observed in the virgin HDPE/mica composites studied by Lapčík et al. ${ }^{7}$. Also, improvement of adhesion and dispersion of minerals (containing muscovite) in a HDPE/ wood/mineral composite system was only achieved by Koohestani et al. after chemical treatment of the minerals ${ }^{14}$. The good adhesion of the rHDPE/mica composites studied in this work can be attributed to the presence of additives in the plastic lumber ${ }^{3}$.

Table 1 summarizes the results obtained for density, hardness and MFI of rHDPE and composites.

The density value of the rHDPE sample is in accordance with literature data ${ }^{3,6}$. The density increased slightly with mica addition, which can be attributed to good matrix/filler adhesion, as seem in the SEM micrographs. This good interaction is probably related to the additives present in the recycled material, which act as plasticizers.

The hardness results for the composites showed the efficacy of the mica to reinforce the r-HDPE matrix ${ }^{15,16}$. Thus, the hardness of composites is determined mainly in the load domain. Only a small contribution is made by the thermoplastic phase. The results indicated a tendency for stabilization of the hardness up to $15 \%$.

The MFI results showed that the viscosity increased with mica addition. The decrease in the melt-flow index with increasing mica content is usually associated with a restriction in the movement of the chains, thus reducing the flow of the material ${ }^{13}$. Furthermore, the MFI increase was smaller for the HDPE/mollusk shell system studied by Melo et al., which was attributed to the small particle size of the fillers, since larger particle size obstructed the polymer chain ${ }^{17}$.

The FTIR results are shown in Figure 3. It can be observed that the spectra related to plastic lumber (r-HDPE) are very similar to the spectra of the virgin HDPE, formed by the repetition of the - $\left(\mathrm{CH}_{2}\right)$ group. The r-HDPE spectra show the three absorption bands associated with the three modes of C-H bending vibrations: stretching in the 2950 and $2850 \mathrm{~cm}^{-1}$ region; bending in the 1350 and $1450 \mathrm{~cm}^{-1}$ region; and rocking in the $700 \mathrm{~cm}^{-1}$ region. Each band is formed by two peaks, since the frequency of a bending vibration depends on the environment. Thus, for polyethylene each peak corresponds to a particular $\mathrm{C}-\mathrm{H}$ configuration. One band is typical of the bending within the polymer chain, while the other corresponds to the $\mathrm{C}-\mathrm{H}$ bending at the ends of the polymer chain. The relative amplitude of one peak over the other depends on the relative importance of each type of bending and its degree of vibration. HDPE also exhibits $\mathrm{C}-\mathrm{C}$ bending, which is normally observed with absorption bands in the $1000-1250 \mathrm{~cm}^{-1}$ region ${ }^{15}$.
As reported by Beran et al., the vibrations of the mica group minerals can be roughly separated into a vibrational region of hydroxyl groups and a lattice vibrational region, comprising vibrations of the $\mathrm{Si}(\mathrm{Al}) \mathrm{O}_{4}$ tetrahedra, the octahedrally coordinated cations, and the highly coordinated interlayer cations $^{16}$. This separation is complete for the high-energy $\mathrm{OH}$ stretching vibrations, occurring in the $3750-3550 \mathrm{~cm}^{-1}$ region. Absorption bands in the $1200-700 \mathrm{~cm}^{-1}$ region are essentially due to Si-O stretching vibrations and are weakly influenced by other vibrations of the crystal structure and their increase in the composite as the mica percentage increases. The Si-O bending vibrations in the $600-300 \mathrm{~cm}^{-1}$ region usually show coupling, with stretching and bending vibrations of the cation-oxygen octahedra occurring in a similar spectral region. Vibrations of the interlayer cations are located in the range of $400-50 \mathrm{~cm}^{-116}$.

Some other bands could be attributed to the additives used to improve the flow of post-consumer polymer during reprocessing of the material. The additives are formed of small molecules and have low viscosity, so they can act as plasticizers, improving the flow of the material and also facilitating the polymer-load interaction ${ }^{15}$. In this work, we observed no chemical interaction between the rHDPE and mica. Other authors have reported they also did not observe a band indicating covalent bonding between polymer and filler, attributing this to the presence of physical interactions ${ }^{15-18}$.

The TG (Figure 4) and DTG curves (Figure 5) of the rHDPE formulations $(95 / 5,90 / 10,85 / 15$ and $80 / 20$ by weight percentage) had the typical HDPE TG and DTG curve shape, with $\mathrm{T}_{\text {onset }}$ in the range of $450-480{ }^{\circ} \mathrm{C}$ and $\mathrm{T}_{\text {endset }}$ between 500 and $520^{\circ} \mathrm{C}$; and with peaks in the DTG curves between 484 and $499{ }^{\circ} \mathrm{C}$, the typical range for this material ${ }^{3,19}$.

The DTG peaks (Figure 5) showed a slight difference in the decomposition rate, which became slower with higher proportion of mica in the composite. Melo et al. and

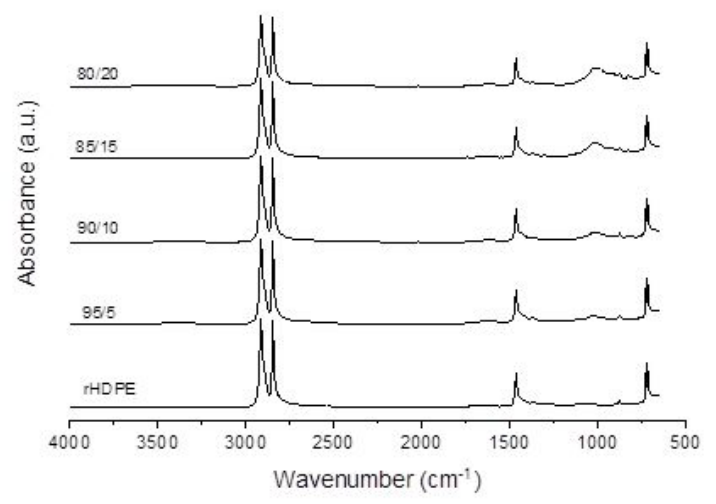

Figure 3. ATR-FTIR spectrum of rHDPE/mica formulations

Table 1. Density, Shore D Hardness and MFI of formulations.

\begin{tabular}{cccc}
\hline Sample (rHDPE/mica) & Density $\left(\mathbf{g} / \mathbf{c m}^{3}\right)$ & Hardness (Shore D) & MFI (g/10min) \\
\hline $100 / 0$ & $0,750 \pm 0,07$ & $16,00 \pm 4,30$ & $0,50 \pm 0,04$ \\
\hline $95 / 5$ & $0,730 \pm 0,07$ & $25,00 \pm 9,43$ & $0,36 \pm 0,04$ \\
\hline $90 / 10$ & $0,782 \pm 0,08$ & $41,20 \pm 6,61$ & $0,35 \pm 0,03$ \\
\hline $85 / 15$ & $0,907 \pm 0,05$ & $56,40 \pm 3,21$ & $0,27 \pm 0,01$ \\
\hline $80 / 20$ & $0,850 \pm 0,06$ & $57,00 \pm 1,22$ & $0,27 \pm 0,01$ \\
\hline
\end{tabular}




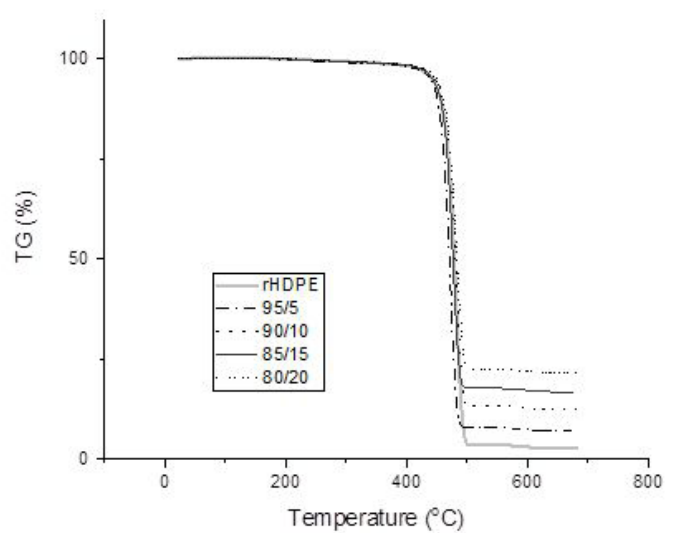

Figure 4. TG curves of rHDPE/mica formulations

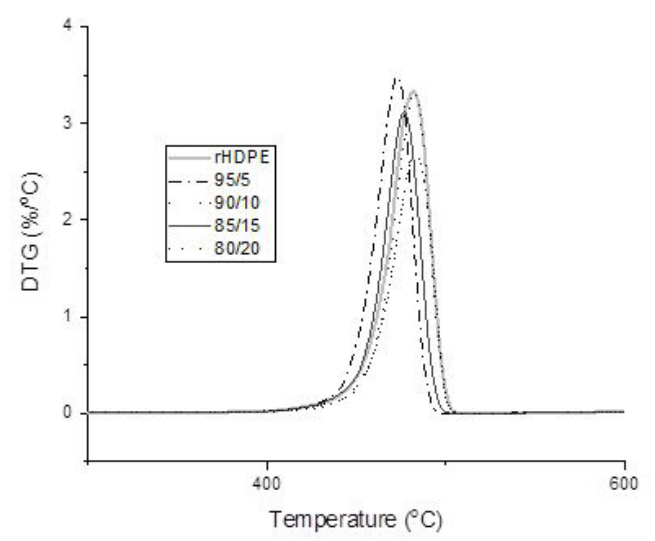

Figure 5. DTG curves of rHDPE/mica formulations

Relosi et al. also observed similar profiles in their works related to polymer/mineral composites. They associated this with the presence of agglomerates and inefficient dispersion of the fillers, suggesting the need to use a coupling agent ${ }^{17,18}$.

As seen in Table 2, analysis of the thermal profile of r-HDPE indicated a final residue percentage of about $2.5 \%$, corresponding to additives incorporated in the material, such as dyes and compatibilizers ${ }^{3,4}$.

The values of the residue content (Table 2) at the end of the $\mathrm{TG}$ analysis were compatible with the dosed residue levels in the samples of each formulation, indicating there were no large losses during processing and also good interaction between the polymer matrix and mineral ${ }^{13}$.

Figure 6 shows the DSC curves of the rHDPE (100/0) and composites $(95 / 5,90 / 10,85 / 15$ and $80 / 20)$. These curves have endothermic peaks between 130 and $150^{\circ} \mathrm{C}$, corresponding to the absorbed heat in the melting of the polymeric material, compatible with the HDPE melting range ${ }^{3}$.

The magnification of the region closest to the melt peak (Figure 7), between $130-150^{\circ} \mathrm{C}$, revealed that the rHDPE/mica samples had slightly lower melting temperatures compared to the rHDPE. This can be also related to the presence of agglomerates and lack of dispersion, as indicated by the DTG results ${ }^{17,18}$. However, considering the results already

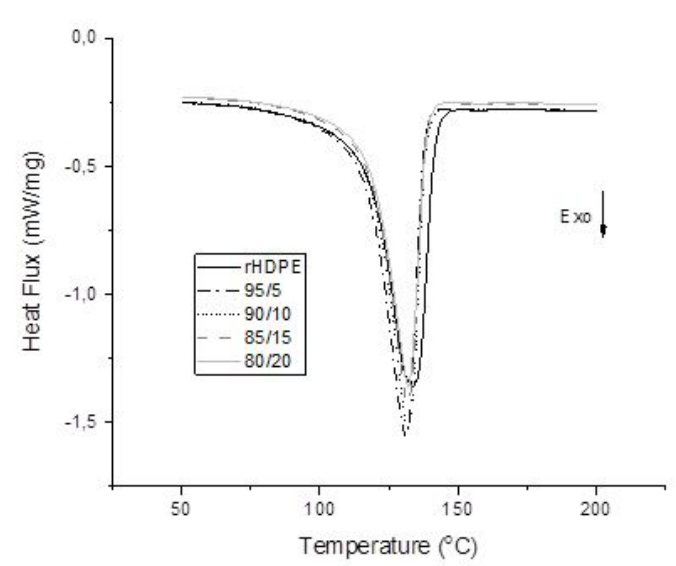

Figure 6. DSC curves (data used are from the second heating) of rHDPE/mica formulations

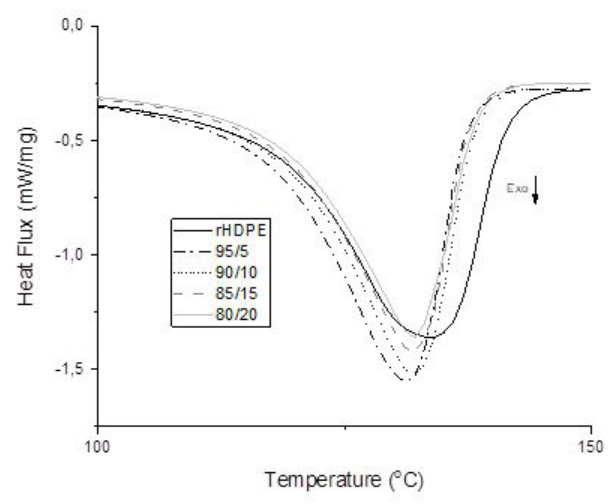

Figure 7. DSC curves magnification of rHDPE/mica formulations

Table 2. Residue contente at the end of thermogravimetric analysis of rHDPE/mica formulations

\begin{tabular}{ccc}
\hline $\begin{array}{c}\text { Sample } \\
\text { (rHDPE/mica) }\end{array}$ & Residue (\%) & $\begin{array}{c}\text { Residue } \\
\text { (without rHDPE \%) }\end{array}$ \\
\hline $100 / 0$ & 2,63 & - \\
\hline $95 / 5$ & 7,02 & 4,39 \\
\hline $90 / 10$ & 12,42 & 9,79 \\
\hline $85 / 15$ & 16,82 & 14,19 \\
\hline $80 / 20$ & 21,57 & 18,94 \\
\hline
\end{tabular}

discussed, which indicate the reinforcement action of mica, these results indicate the interaction between the mineral and the polymer is physical, as also observed by FTIR.

\section{Conclusions}

In this study, the influence of muscovite mica concentration (0-20\%) in the HDPE/mica composites was investigated. The results of density, hardness and MFI pointed to the reinforcing action of mica in the composite, but also demonstrated that up to $15 \%$ mica, the mechanical reinforcement was smaller, possibly due to saturation of mica in the composite. 
The results of thermal analysis (TG, DTG and DSC) were compatible with the results of the HDPE and HDPE/ mineral systems but also suggested the possible presence of agglomerates and/or inefficient dispersion of the fillers.

The images obtained by SEM indicated good interaction between the matrix and filler, which was attributed to the additives present in the plastic lumber. The FTIR spectra also revealed physical interaction (without evidence of chemical bonding).

Thus, the obtained rHDPE/mica composites can be considered sustainable since the polymeric matrix is recycled and the muscovite used has low value. Also, the materials were prepared without the use of compatibilizers.

\section{Acknowledgements}

We thank FAPERJ (Rio de Janeiro State Research Foundation), Comlurb and CETEM.

\section{References}

1. Singh N, Hui D, Singh R, Ahuja IPS, Feo L, Fraternali F. Recycling of plastic solid waste: A state of art review and future applications. Compos, Part B Eng. 2017;115:409-22.

2. Carrol DR, Stone RB, Sirignano AM, Saindon RM, Gose SC, Friedman MA. Structural properties of recycled plastic: sawdust lumber decking planks. Resour Conserv Recycling. 2001;31:241-51.

3. Martins S, Barros MM, Pereira PSC, Bastos D. Use of manufacture residue of fluidized-bed catalyst-cracking catalysers as flame retardant in recycled high density polyethylene. J Mater Res Technol. 2019;8(2):2386-94.

4. Guimarães LFC. Avaliação dos aspectos técnicos e econômicos na produção de madeira plástica por meio da utilização de materiais reciclados [dissertation]. Minas Gerais: Universidade Federal de Minas Gerais; 2013.

5. Wei L, McDonald AG, Freitag C, Morrell JJ. Effects of wood fiber esterification on properties, weatherability and biodurability of wood plastic composites. Polym Degrad Stabil. 2013;98:1348-61.

6. Gerardo CF, França SCA, Santos SF, Bastos DC. A study of recycled high-density polyethylene with mica addition: influence of mica particle size on wetting behavior, morphological, physical, and chemical properties. IJDR. 2020;10(06):37223-8.
7. Lapčík L, Maňas D, Lapčíková $B$, Vašina $M$, Staněk $M$, Čépe K, et al. Effect of filler particle shape on plastic-elastic mechanical behavior of high density poly(ethylene)/mica and poly(ethylene)/wollastonite composites. Compos, Part B Eng. 2018;141:92-9.

8. Marinelli AL, Monteiro MR, Ambrósio JD, Branciforti MC, Kobayashi M, Nobre AD. Desenvolvimento de compósitos poliméricos com fibras vegetais naturais da biodiversidade: uma contribuição para a sustentabilidade amazônica. Polímeros. 2008;18(2):92-9.

9. Santos SF, França SCA, Ogasawara T. Method for grinding and delaminating muscovite. Min Sci Technol. 2011;21(1):7-10.

10. Dana, JD. Manual de mineralogia. Rio de Janeiro: Editora AS; 1959. (Livros Técnicos e Científicos).

11. Turku I, Kärki T, Puurtinen A. Durability of wood plastic composites manufactured from recycled plastic. Heliyon. 2018;4(3):1-20.

12. Jumadi MT, Muhd MR, Mustafa Z. Characterisation of wood plastic composite manufactured from kenaf fibre reinforced. Compos Struct. 2018;189:510-5.

13. Monsores KGC, França SCA, Moraes LS, Santos SF. Materiais compósitos à base de PP e muscovite. Rev Iberoam Polim. 2017;18:301-9.

14. Koohestani B, Darban AK, Yilmaz E, Mokhtari P, Ganetri I. Influence of amine and vinyl functional groups of silanes on total performance of thermoplastic-based composites. Constr Build Mater. 2018;172:98-105.

15. Torres AVA, D'Almeida JRM, Habas J-P. Avaliação do efeito de um óleo parafínico sobre o comportamento físico-químico de tubulações de polietileno de alta densidade. Polímeros. 2010;20(5):331-8.

16. Beran A. Infrared Spectroscopy of Micas. Rev Mineral Geochem. 2002;46(1):351-69.

17. Melo PMA, Macedo OB, Barbosa GP, Ueki MM, Silva LB. High-density polyethylene/mollusk shell-waste composites: effects of particle size and coupling agent on morphology, mechanical and thermal properties. J Mater Res Technol. 2019;8(2):1915-25.

18. Relosi N, Neuwald OA, Zattera AJ, Piazza D, Kunst SR, Birriel EJ. Effect of addition of clay minerals on the properties of epoxy/ polyester powder coatings. Polímeros. 2018;28(4):355-67.

19. Banat R, Fares MM. Thermo-gravimetric stability of high density Polyethylene composite filled with olive shell flour. Am J Pol Sci. 2015;5:65-74. 